\title{
Variação da composição e estrutura da assembleia de diatomáceas do Páramo de Frontino (Cordilheira Ocidental dos Andes, Colômbia) durante o Holoceno
}

\author{
Omaira Rosa SIERRA-ARANGO ${ }^{1} \&$ Paulo A. SOUZA ${ }^{1,2}$ \\ 1. Programa Pós-graduação em Geociências Universidade Federal do Rio Grande do Sul. Av. Bento Gonçalves, 9500, CEP 91540-000, Porto \\ Alegre, RS. E-mail: arangosierra@yahoo.com. \\ 2. Laboratório de Palinologia Marleni Marques Toigo, Instituto de Geociências, Universidade Federal do Rio Grande do Sul. Av. Bento Gon- \\ çalves, 9500, CEP 91540-000, Porto Alegre, RS. E-mail: paulo.alves.souza@ufrgs.br.
}

Recebido em 09/2013. Aceito para publicação em 11/2013.

Versão online publicada em 04/12/2014 (www.pesquisasemgeociencias.ufrgs.br)

\begin{abstract}
Resumo- Neste trabalho é apresentada a variação temporal da composição e estrutura da assembleia de diatomáceas da Bacia Llano Grande, Páramo de Frontino, localizado a $3.460 \mathrm{~m}$ de altitude ao nordeste da Cordilheira Ocidental dos Andes, Colômbia. 0 material estudado é referente a um testemunho de 8,5 m perfurado na porção central da bacia, do qual 57 níveis holocênicos foram aleatoriamente amostrados para o estabelecimento da composição taxonômica da assembleia e sua densidade. Um total de 292 táxons foi reconhecido, incluindo 149 com nomenclatura taxonômica aberta, em nível de gênero. Estes últimos táxons podem correspondem a variações intraespecíficas de formas conhecidas ou novas espécies, demonstrando a riqueza biológica destes ambientes, sujeitos a condições particulares de estresse. Uma alta variabilidade na densidade, na composição e estrutura da assembleia de diatomáceas foi verificada ao longo do perfil sedimentar, com desaparecimento de 169 táxons, representando uma perda de 40,9 \% da composição taxonômica. Os desaparecimentos são atribuídos a mudanças de temperatura, aportes externos de cinzas vulcânicas, desmineralização e diminuição da profundidade do corpo d'água. No trecho correspondente ao Holoceno inicial, as oscilações na composição, densidade e na estrutura da assembleia de diatomáceas são atribuídas a perturbações físicas e químicas da coluna d'água, que motivaram a diminuição da densidade e a substituição da maioria das espécies do intervalo por outras nos níveis correspondentes ao Holoceno médio e final. No Holoceno médio as variações são devidas às oscilações do volume e desmineralização do corpo d'água e ao aporte externo de cinzas dos vulcões. No final do Holoceno, as variações taxonômicas estão relacionadas à progressiva diminuição do nível d'água do ecossistema e colonização por macrófitas.
\end{abstract}

Palavras-chaves: diatomáceas, páramo, trópico, composição e estrutura, paleoecologia, paleolagos.

\begin{abstract}
Holocene CHANGES IN THE COMPOSITION AND STRUCTURE OF DiaTOMS ASSEMBLAGES FROM THE Frontino PÁramo (Occidental Andes CoRdillera, Colombia). This paper presents the analysis of temporal variation in composition and structure of Holocene diatom assemblages from the Llano Grande Basin, Frontino Páramo, located at 3,460 msnm in the northern portion of the Occidental Andes Cordillera Occidental, Colombia. The interval analyzed is constituted of $8.5 \mathrm{~m}$ of a core drilled in the central portion of the basin, corresponding to the Holocene. 57 levels were randomly sampled and permanent slides were prepared, from which the taxonomic composition of the assemblages and respective densities were performed. A high variability in the density, composition and structure of the diatoms assemblages was established. 292 species were recognized, including 149 with open taxonomic nomenclature, recognized at genus level. These last taxa should correspond to intraspecific variations of known species or new ones, demonstrating the biological richness of these environments, subject to particular stress conditions at high altitude. Along the core, 169 taxa disappeared, representing a loss of $40.9 \%$ in taxonomic composition. These disappearances are attributed to environmental changes related to temperature, foreign input of volcanic ashes, demineralization and decrease in depth of the water column. In the interval correspondent to the early Holocene, strong environmental disturbances, as well as physical and chemical variations were recorded, with effect on the diatoms assemblage, causing drastic density reduction and change in the compositions towards the levels corresponding to the middle and late Holocene. Changes in the middle Holocene are interpreted as fluctuations in the volume and demineralization of the water body and the external addition of volcanic ashes. In the late Holocene, changes are related to the progressive decrease of the water level in the ecosystem and colonization by macrophytes.

Keywords: diatoms, páramo, tropic, composition and structure, paleoecology, paleolakes.
\end{abstract}

\section{Introdução}

Segundo Chapin \& Körner (1995) e Falasco et al. (2012), a riqueza de espécies tende a ser limitada nos ecossistemas de altitude devido às condições extre- ma de luz ultravioleta, baixa temperatura, isolamento, coluna d'água desmineralizada, entre outras varáveis. Para a faixa neotrópica, o fitoplâncton endêmico começa a desaparecer a $2.500 \mathrm{~m}$ de altitude (Coesel, 1992; Donato, 2004), sendo sua estrutura e dinâmica 
influenciadas pela intensidade de luz, disponibilidade de nutrientes, movimentos da coluna d'água (Margalef, 1983; Reynolds, 1984; Kinzie et al., 1998; Wetzel, 2001; Lewis, 2002; Leavitt et al., 2003) e interações biológicas (Tilman, 1982). Rivera \& Donato (2008) demonstraram que a variação na composição da comunidade de diatomáceas e a diversidade desses ecossistemas na Colômbia estão mais relacionadas com o caudal do que com qualquer outro fator ecológico. Para Barbosa (2009) a distribuição e a dinâmica do fitoplâncton de altitude são controladas por todas as variáveis expostas anteriormente. No entanto, a distribuição espacial e a dinâmica do fitoplâncton na Laguna Sabanas, Páramo de Belmira (Colômbia) apresentam maior correlação com a precipitação do que com outras variáveis ambientais (Barbosa \& Sierra-Arango, submetido).

Os estudos sobre o fitoplâncton e o perifiton de ambientes lóticos e lênticos da Colômbia tem sido incrementados nos últimos anos. No entanto, são poucos os trabalhos que incluem unicamente as diatomáceas de ambientes atuais e subrecentes. Essas pesquisas têm sido realizadas por Sala et al. (2002), Ramírez \& Plata-Díaz (2008), Montoya-M et al. (2008), Sala et al. (2008 a, b), Vouilloud et al. (2010), Abuhatab-Aragon (2011), Mejia (2011), Pedraza-Garzón \& Donato-Rondón (2011), que estabeleceram a composição taxônomica e a estrutura das diatomáceas em distintos ecossistemas. Outros estudos foram realizados usando as diatomáceas atuais e subrecentes como indicadoras ambientais (Díaz-Quiróz \& Rivera-Rendón, 2004; Sierra \& Monsalve, 2005; Morales-Duarte et al., 2010). Na Colômbia, os estudos paleoecológicos com base em diatomáceas foram realizados a partir do período glacial tardio. Lozano et al. (1999) estabeleceram a composição e estrutura da assembléia de diatomáceas da Lagoa Puente Largo, Páramo de Frontino e propôs a reconstrução do estado trófico e inferências de hábitat e salinidade durante o Holoceno. As contribuições de Velez et al. (2003, 2005abc, e 2006) são advindas de diferentes turfeiras de altitude, com reconstruções paleolimnológicas dos sistemas lacustres. Sierra \& Monsalve-M (2005) analisaram os ambientes atuais e subrecentes objetivando a determinação da variação e reconstrução do estado trófico da zona úmida Humedal de Jaboque (Bogotá, Colômbia). Nesse mesmo ecossistema, Sierra (2007) estabeleceu a variação espaço-temporal da composição e estrutura das diatomáceas dos últimos 1.500 anos, constituindo o primeiro trabalho realizado na Colômbia que se focalizou na análise da composição e a estrutura de diatomáceas não atuais. 0 estabelecimento da variação da composição e da estrutura da assembleia de diatomáceas holocênicas em ecossistemas de páramos de Colômbia se faz importante, por tratar um ambiente extremo e contribui para desvendar e ampliar a informação taxonômica destes microfísseis.

Este trabalho objetiva estabelecer a variação temporal da composição e a estrutura da assembleia de diatomáceas holocênicas da Bacia Llano Grande, Pára- mo de Frontino (Departamento de Antioquia, Colômbia), a partir de amostras de um testemunho de sondagem, datado no Holoceno $\left(\mathrm{C}^{14}\right)$. Variações ambientais causaram efeitos drásticos nas comunidades bióticas, gerando novas trocas de indivíduos e novas sucessões ecológicas (Valero-Garces et al., 1998; López-Merino et al., 2011). Como consequência, as assembleias de diatomáceas holocênicas do Páramo de Frontino constituem ferramentas de reconstrução ecológica e ambiental.

\section{2 Área, materiais e métodos}

\section{1 Área de estudo}

O Páramo de Frontino está localizado ao norte da Cordilheira Ocidental dos Andes, Departamento de An-

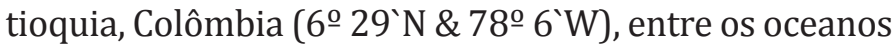
Atlântico e Pacífico, com uma área de $25 \mathrm{~km}^{2}$, constituindo a principal elevação da região (Parra, 1991). A área recebe influências secas provenientes do Caribe, atenuadas, na parte norte, pelo Morro Paramillo e pelas correntes muito úmidas da Bacia do Chocó (Fig. 1). Essas últimas influenciam significativamente o clima no Páramo, resultando em condições muito úmidas na maior parte do ano (Velásquez, 2005). A área apresenta um regime de precipitação bimodal com temperatura diurna do ar mais alta do que da água; no período noturno a temperatura da água é de $12{ }^{\circ} \mathrm{C}$ e do ar oscila entre $1,9^{\circ} \mathrm{C}$ e 12 ${ }^{\circ} \mathrm{C}$ (Jaramillo \& Parra, 1993; Abril, 2007).

O ecossistema Páramo se desenvolve desde os $3.450 \mathrm{~m}$ até a máxima altitude de $4.080 \mathrm{~m}$. A vegetação está dominada por Espeletia (Muts ex Humb. \& Bonp), árvore típica na região, com diversidade de gramíneas. Apresenta ambientes pantanosos, turfeiras, lagoas, lagunas, lagos, cachoeiras e rios (Parra, 2005; Velásquez, 2005; Velásquez \& Hooghiemstra 2013). 0 solo é classificado como andisol, originado por materiais vulcânicos; no entanto, na planície de Puente Largo, dominam os solos do tipo histossol (organossolos), formados pela acumulação da matéria orgânica. As lagoas atuais no Páramo são de origem glacial, com organossolos fibrosos, lodo orgânico e solos circundantes.

\subsection{Amostragem}

0 testemunho Llano Grande 3 (LLG3), com um total de $12 \mathrm{~m}$ de profundidade, foi coletado em 2007 pelo Grupo de Investigações de Palinologia e Paleoecologia da Universidade Nacional da Colômbia, sede Medellín (UNALMED), em associação com a Universidade de Genebra, Suíça. A descrição dos parâmetros que se perdem com o tempo (cor, o estabelecimento de mudanças na composição geral do sedimento), e o fatiamento da amostragem foi realizada in loco. Cada centímetro amostrado foi armazenado e transportado até a UNALMED. De acordo com as datações radicarbônicas e a análise estratigráfica de Parra (2005) e Muñoz (2012), o testemunho compreende todo o Holoceno, apresentando alto conteúdo de matéria orgâ- 


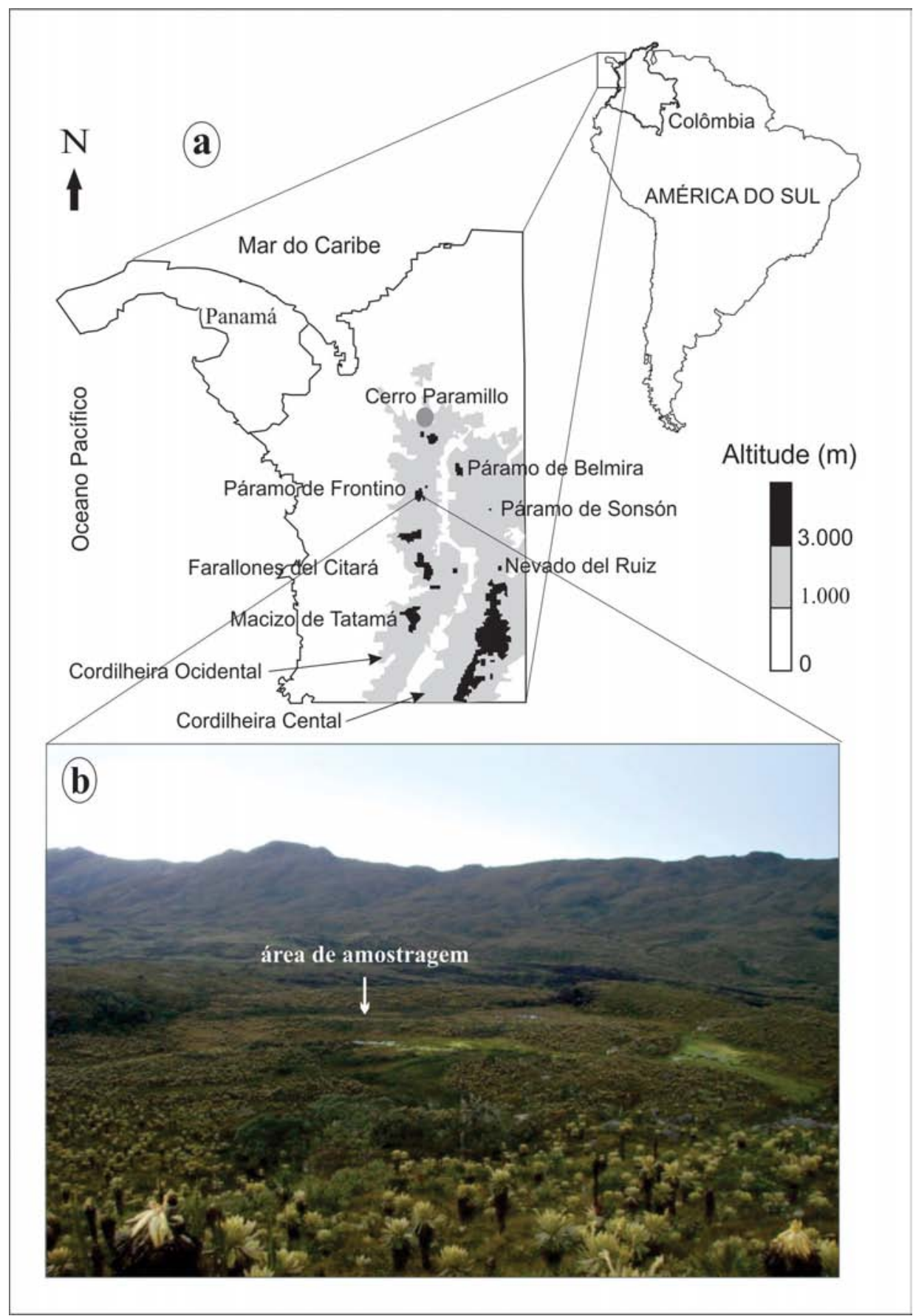

Figura 1. Localização da área. A) Páramo de Frontino, Departamento de Antioquia, Colômbia. B). Diferentes ambientes atuais da Bacia Llano Grande e a área de amostragem.

nica, com pouca ou nula variação na coloração entre as tonalidades da cor marrão escuras.

Segundo Parra (2005), a taxa de sedimentação do pacote sedimentar é de $1 \mathrm{~mm} /$ ano. Este trabalho é baseado no estudo do trecho $8,51 \mathrm{~m}$ de profundidade. 0 trecho entre 851 e $578 \mathrm{~cm}$ de profundidade é posicionado no Holoceno inicial, com datações entre $10.000 \mathrm{e}$ 7.000 anos AP; o intervalo entre corresponde é relativo ao médio ( 7.000 a 5.000 anos AP) a 536 até $181 \mathrm{~cm} \mathrm{de}$ profundidade; enquanto para o Holoceno final (5.000 até a atualidade), 181 até $1 \mathrm{~cm}$ de profundidade. Todo o testemunho amostrado é constituído por lama, com alta concentração de matéria orgânica. No intervalo basal (Holoceno inicial) o aspecto é maciço; a partir da profundidade a $578 \mathrm{~cm}$ ocorrem raízes e outros restos vegetais, com concentração variada, e tendência de au- mento em direção ao topo.

Nos primeiros $851 \mathrm{~cm}$ de profundidade, utilizando uma seringa de $5 \mathrm{~cm}^{3}$ para cada nível, foram coletadas aleatoriamente, 57 amostras, de $1 \mathrm{~cm}^{3}$ cada, guardadas em sacola plástica Sellomatic, para a análise da variação temporal da composição e a estrutura das diatomáceas. As amostras foram transportadas e processadas no Laboratório de Palinologia Marleni Marques Toigo do Instituto de Geociências da Universidade Federal do Rio Grande do Sul (LPMMT/IG/UFRGS), Porto Alegre, Brasil. A técnica de extração e limpeza das valvas de diatomáceas seguiu a metodologia de Simonsen (1974), modificada por Moreira-Filho \& Valente-Moreira (1981). Lâminas permanentes foram elaboradas com $10 \mu \mathrm{l}$ de cada resíduo, utilizando Naphrax como meio de colagem. 0 reconhecimento taxonômico e as 
análises subsequentes (densidade, grau de fragmentação e dissolução) foram realizados utilizando-se microscópio Olympus CX31, em aumento de 1000x. Adicionalmente, imagens de microscopia eletrônica de varredura foram obtidas, em níveis selecionados. A densidade de cada espécie, por nível, foi estimada a partir da totalidade das diatomáceas presentes em cada lâmina, referente a um volume de $10 \mu \mathrm{L}$, em varredura em forma de "zig-zag" de modo a evitar sobreposição de leitura de campos.

\subsection{Análise taxonômica e de representatividade quantitativa}

O reconhecimento taxonômico foi efetuado com base nas obras de Schmidt (1874-1959), Hustedt (1930), Frenguelli (1945), Patrick \& Reimer (1966, 1975), Krammer (1997ab) Krammer \& Lange-Bertalot (1986, 1991ab, 1997ab), Lange-Bertalot \& Genkal, (1999), Round et al. (1990), Reichardt \& Lange-Bertalot (1991), Krammer (1992, 1997 ab, 2000), Lange-Bertalot \& Moser (1994), Lange-Bertalot et al. (1996), Metzeltin \& Longe-Bertalot (1998), Lange-Bertalot \& Genkal (1999), Rumrich et al. (2000), Houk (2003), Bicudo \& Menezes (2006), Lange-Bertalot (2007), Houk et al. (2010), Lange-Bertalot et al. (2011), Morales et al. (2011), entre outros. Seguiu-se o sistema de classificação de Round et al. (1990) e as tipologias de cada espécie conforme Lange-Bertalot et al. (2013).

Como descritores estatísticos da densidade e da estrutura da assembleia das diatomáceas foram utilizados os valores da média, os limites absolutos (máximo e mínimo) e o desvio padrão. A permanência e a variação taxonômica das espécies ao longo do testemunho foram estabelecidas através da análise de distribuição do diagrama de Carretel (Spindle diagram). A diversidade específica, a dominância e a equidade da assembleia de diatomáceas foram obtidas com o apoio dos programas PAST (Hammer et al. 2001) e Microsoft Excel 2010. A significância estatística entre as divisões do Holoceno foi revelada através da análise de propor- ções utilizando a qui-quadrado e Kruskal Wallis, ambas realizadas com o programa IBM SPSS Statistics 21.0. As espécies com densidades totais menores que 100 valvas/ $\mu \mathrm{L}$ foram excluídas da análise, de modo a evitar o erro estatístico tipo I.

\section{Resultados}

\subsection{Composição das assembleias de diatomáceas}

No testemunho LLG3, foram registradas 11 ordens, 21 famílias, 43 gêneros, 148 espécies, 49 espécies em conferatur e 95 tipificadas e numeradas como "sp.". Entre os 43 gêneros, oito correspondem a formas cêntricas e as demais penadas. 0 gênero Eunotia (Ehr) apresentou a maior riqueza de espécies (109), que equivale a $37 \%$ do total registrado, seguindo-se os gêneros Pinnularia (Ehr) (21 espécies), Encyonopsis (Kram) (17), Encyonema (Kütz) (16), Gomphonema (Agar) (14), Navicula (Bor) (13), Brachysira (Kütz) (12), Frustulia (Agar) (10), Actinella (Lew.) Fragilaria (Lynb.) e Cymbopleura (Kram.) Kram. (7 cada um), Neidium (Pfi.), Caloneis (Clev.) e Diploneis (Ehr) (5), Aulacoseira e Nitzschia (Hass.) (4), Surirela (Tur.) e Melosira (Agar.) (3), Cyclotella (Kütz.), Cymbella (Agar.), Diadesmis (Kütz), Hantzschia (Gru), Kareyevia (Rou \& Buk), Stenopterobia (Bré), Stauroneis (Ehr.) e Staurosira (Ehr.) (2); os demais gêneros são representados por 1 espécie: Echnanthes (Bor.), Achnanthidium (Kütz.), Adlafia (Moser, Lang-Bert. \& Met.), Asterionella (Hass.), Cavinula (Man. \& Stic.), Desmogonium (Ehr.), Kobayasiella (Lang-Bert), Luticola (Mann.) Meridion (Agar.), Naviculadicta (Witk. Lang-Bert. \& Met.), Nupela (Viver. \& Camp.), Planothidium (Roun. \& Buk.), Psammothidium (Buk. \& Roun.), Sellaphora (Meres.), Semiorbis (Patric.) e Tabellaria (Ehr.). 0 gênero Eunotia também apresentou a maior densidade, seguido de Aulacoseira, Melosira e Brachysira. Os gêneros Adlafia, Naviculadicta, Desmogonium, Luticola, Asterionella e Nupela ocorrem com densidades menores de 100 valvas/ $\mu$ L (Fig. 2).

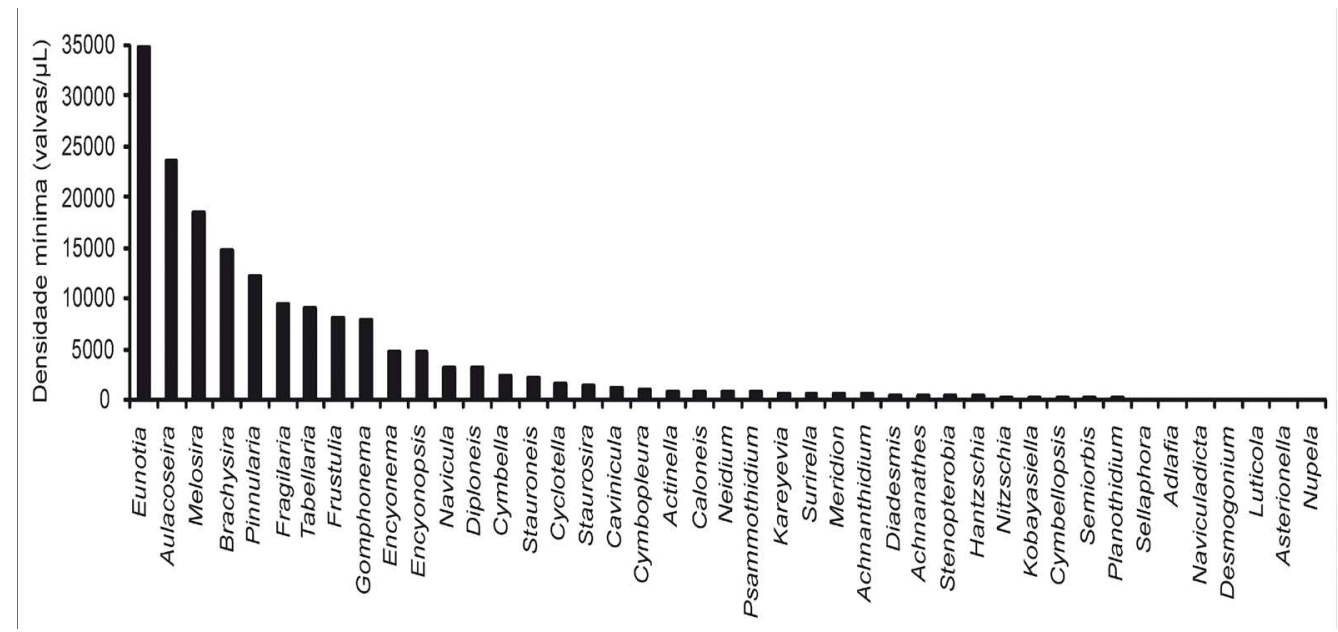

Figura 2. Densidade dos principais gêneros de diatomáceas holocênicas do testemunho LLG3, Bacia Llano Grande, Páramo de Frontino, Departamento de Antioquia, Colômbia. 
Do total de espécies registradas, 177 apresentaram densidade superior a 100 valvas/ $\mu \mathrm{L}$, entre elas Eunotia andinofrequens Lang-Bert. (espécie com maior densidade ao longo de todo o Holoceno com 9.650 valvas/ $\mu \mathrm{L}$ ), seguida de Tabellaria flocculosa (Roth) Kütz. (9.172 valvas $/ \mu \mathrm{L}$ ), Aulacosiera tenuior (Grun) Kramm. (8.324 valvas $/ \mu \mathrm{L}$ ), Brachysira brebissonii (Ross) (8.098 valvas $/ \mu \mathrm{L}$ ), Aulacoseira scalaris (Gruin van Heur.) Hou. Kle. \& Pass. (7.222 valvas $/ \mu \mathrm{L})$, Aulacoseira distans (Ehr.) Simon. (5.225 valvas/ $\mu \mathrm{L}$ ), Melosira cf. dickiei (Thw.) Kütz. (5.009 valvas/ $\mu \mathrm{L}$ ), Melosira varians (Agar.) (3.891 valvas/ $\mu \mathrm{L}$ ), Melosira sculpta (Ehr.) Kütz. (3.727 valvas/ $\mu \mathrm{L}$ ) (Fig. 3), Eunotia georgii (Metz. \& Lange-Bert.), Navicula sp. 1, Nitzschia sp. 1 (1 valva/ $\mu \mathrm{L}$ ), Actinella puntata (Lew.), Cymbella sp. 1, Navicula sp. 3 (cada com 2 valvas/ $\mu \mathrm{L}$ ), Eunotia sudetica (Müll) (3 valvas/ $\mu \mathrm{L}$ ), Encyonema cf. strictum (Clev-Eul.) Kram, Eunotia cf. papilioforma (Furey, Lowe \& Johan), Eunotia sp. 17, Neidium sp. 2, Nupela cf. astartiella (Metz. \& Lange-Bert.) (4 valvas $/ \mu \mathrm{L}$ ), com menores densidades (Fig. 3).

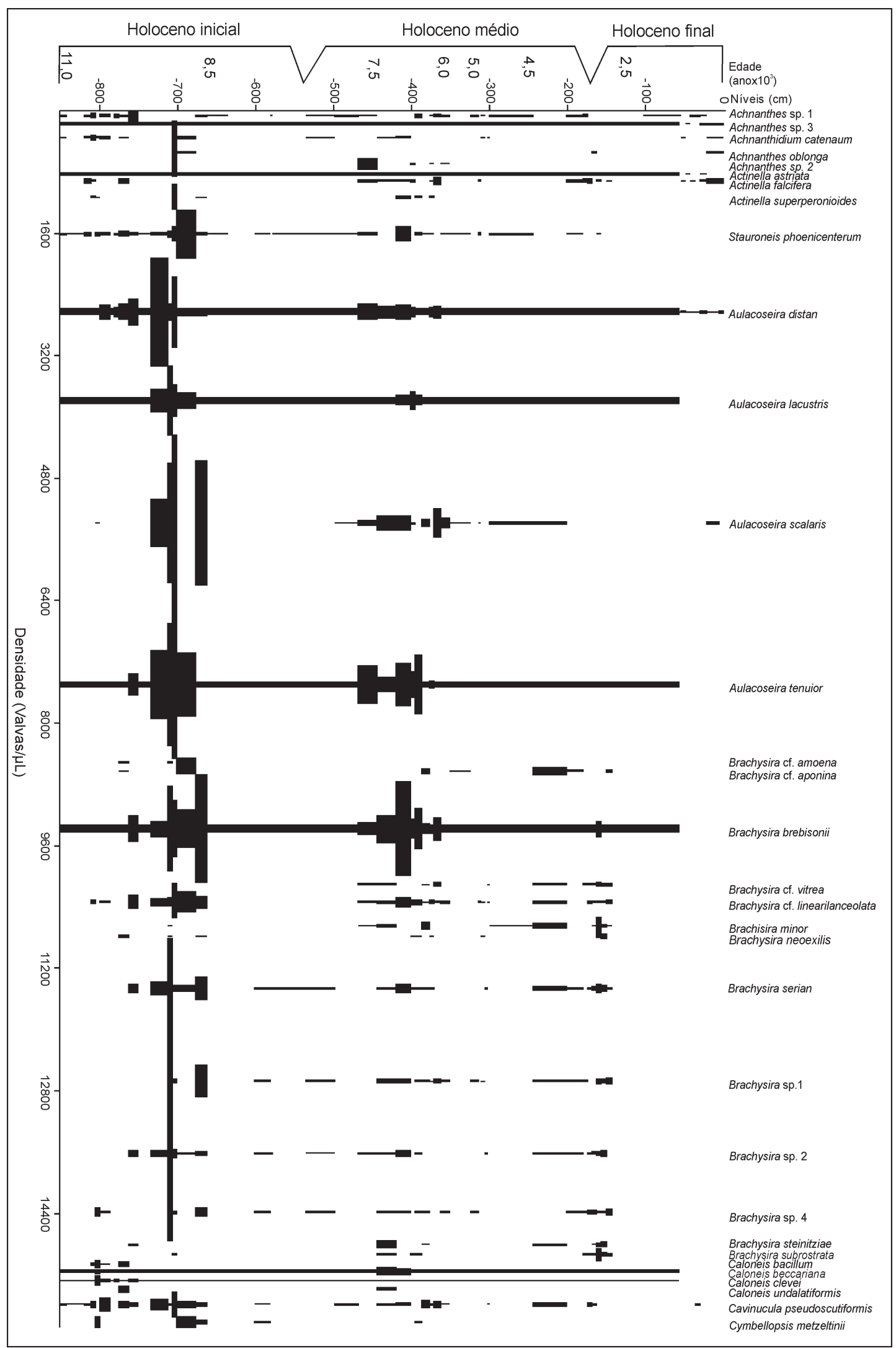




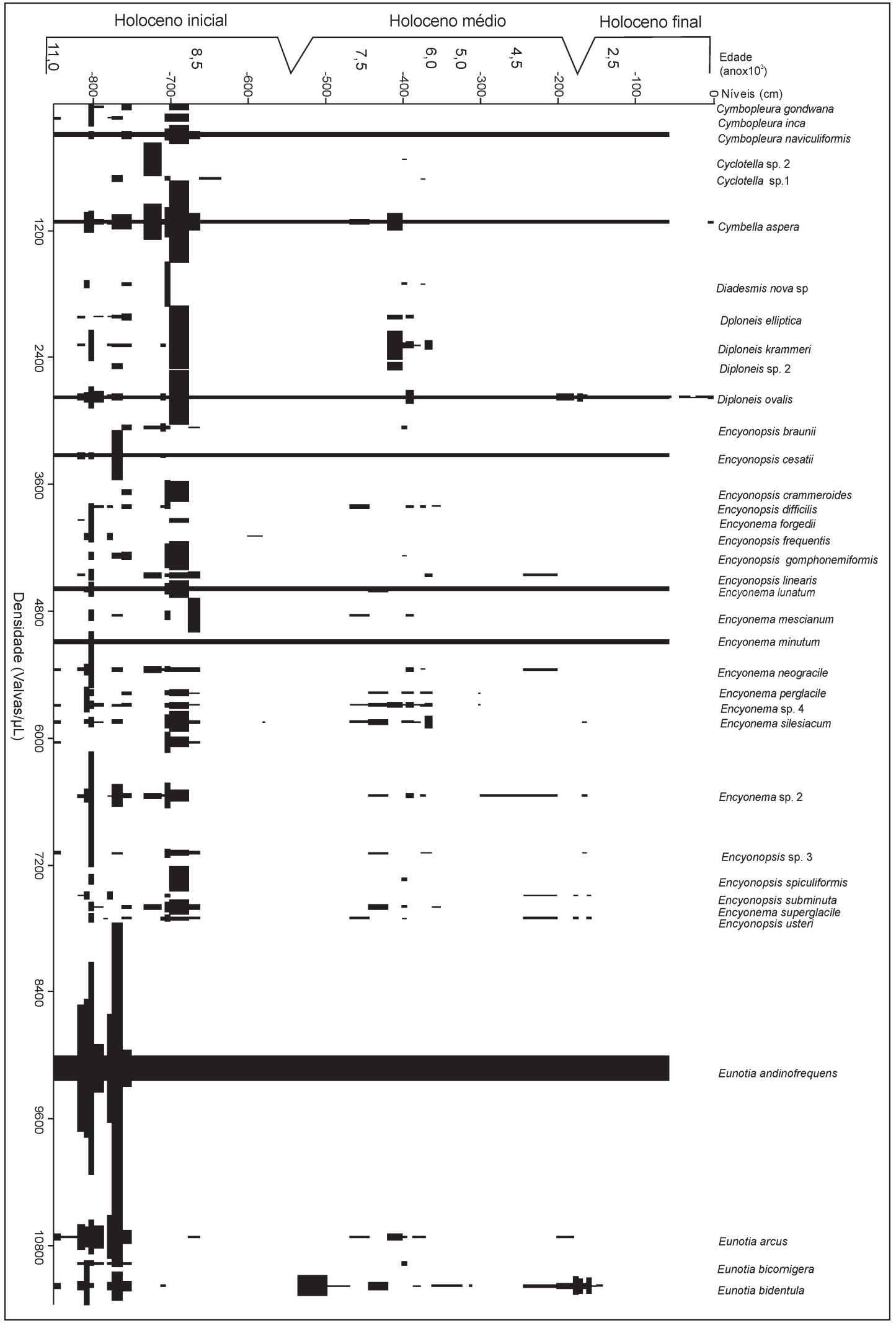




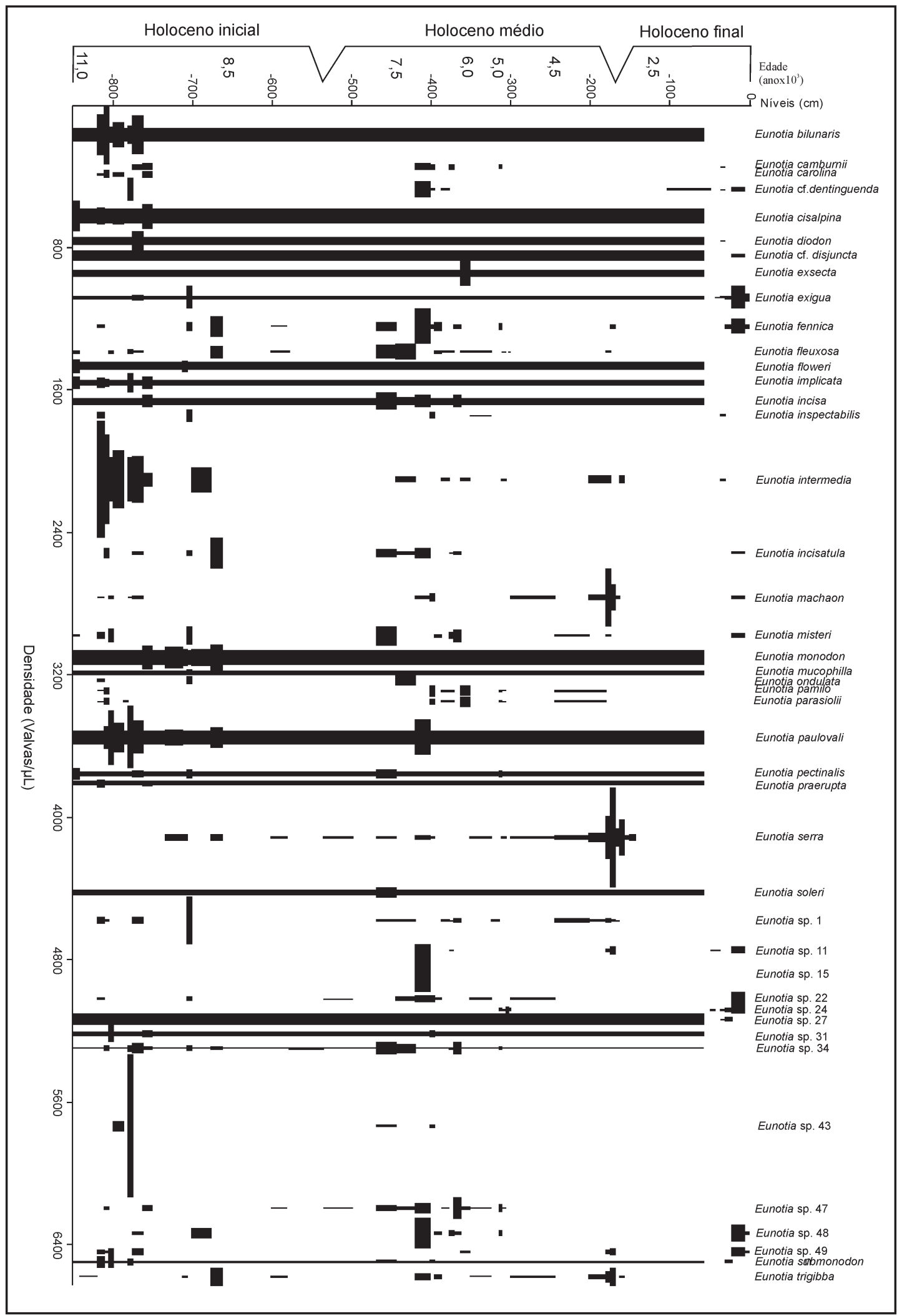




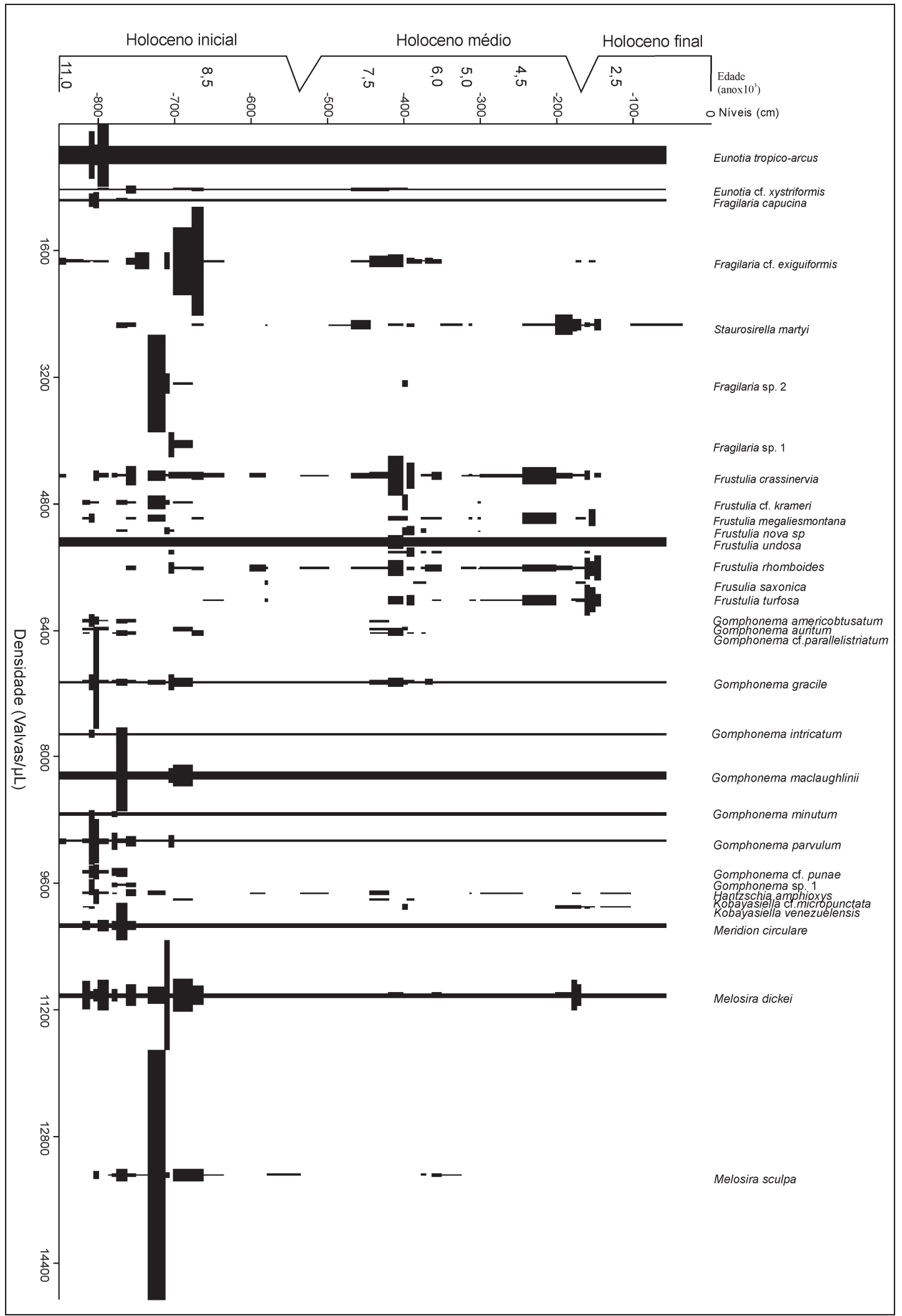




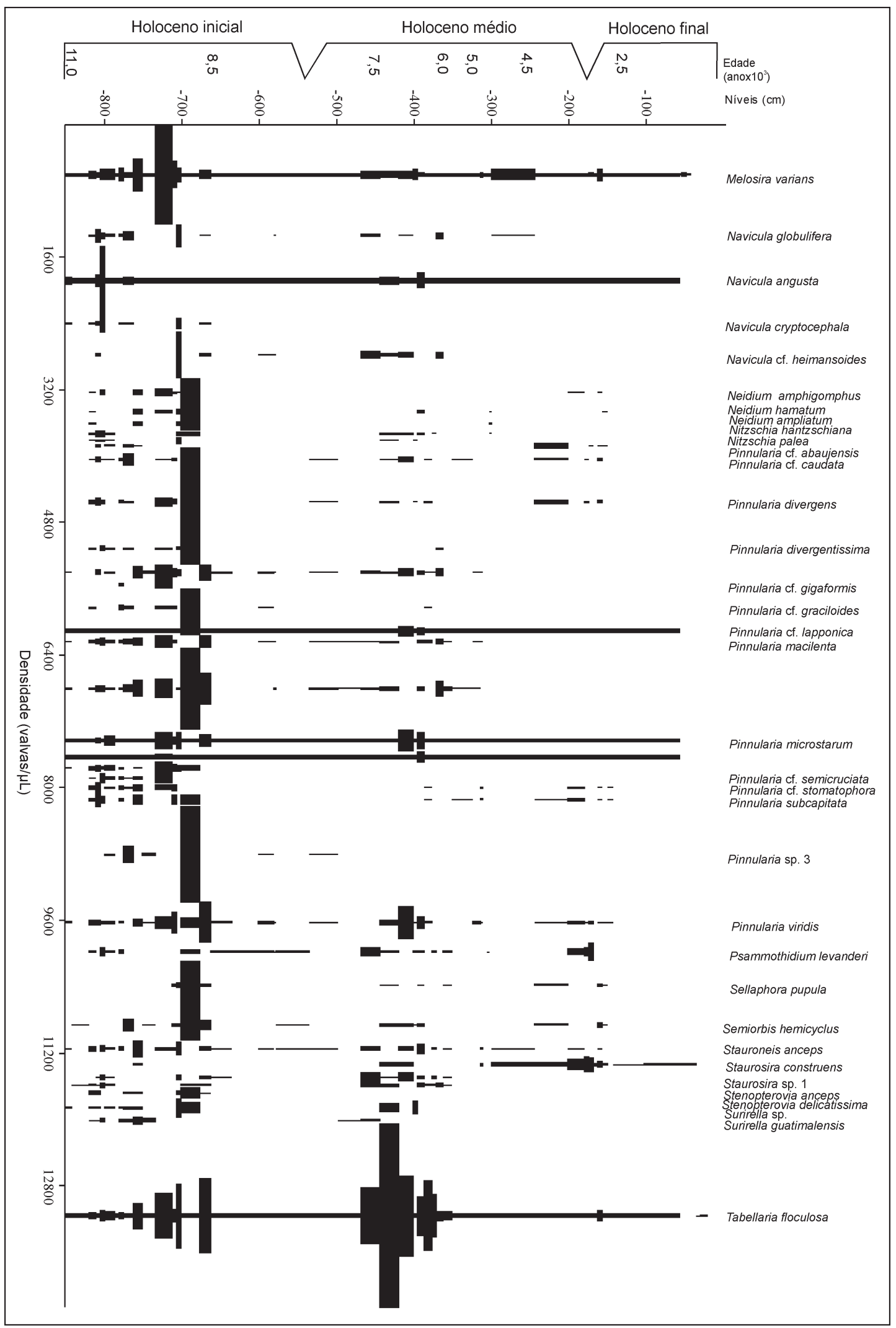

3.2 Permanência da assembleia de diatomáceas no intervalo amostrado

Dentre as espécies identificadas, 88 espécies ocorreram em todo o Holoceno. Dentre estas, apenas cinco foram registradas em pelo menos 30 níveis estratigráficos, dos 57 analisados. M. varians é a espécie com maior permanência no testemunho, ocorrendo em 46 níveis. A. distan foi registrada em 44 níveis, $F$ crassinervia em 34, T. flocculosa em 33, B. brebissonii em 32, M. cf. dickiei em 31, e Eunotia bilunaris (Ehr.) Schaa. e $S$. phoenicenterum (Nitz) Ehr. em 30 níveis cada (Fig. 3).

As 196 espécies restantes foram registradas de forma restrita para alguma divisão do Holoceno, sendo 67 exclusivas do Holoceno inicial, 30 do Holoceno médio e 8 do Holoceno final. Além disso, 71 espécies ocorrem entre o Holoceno inicial ao médio e 9 entre o Holoceno médio ao final (Fig. 3).

E. andinofrequens, $A$. scalaris, $A$. tenuior, B. brevissonii, M. cf. dickiei, A. distans e M. sculpta apresentaram 
maior densidade no Holoceno inicial, nesta ordem, enquanto Gomphonema angustatum (Kütz.) Raben, E. cf. strictum, E. cf. papilioforma, Eunotia sp. 17 e N. cf. astartiella mostraram os menores valores para essa variável no mesmo intervalo (Fig. 3).

No Holoceno médio, T. flocculosa, B. brevissonii, $A$. tenuior, Frustulia crassinervia (Bréb), A. distans e A. scalaris são registradas com a maior densidade. No entanto, Navicula sp. 3, Encyonopsis krammeri (Reich), Adlafia bryophila (Moser, Lange-Bert. \& Met.), Navicula sp. 1 e Nitzschia sp. 1 apresentaram densidades menores de 3 valvas/ $\mu$ L (Fig. 3 ).

No Holoceno final, Eunotia serra (Ehr.), Frustulia rhomboides (Ehr.), Staurosirella martyi (Hérib) e $M$. cf. dickiei, nesta ordem, apresentaram maior densidade, enquanto Pinnularia gibba (Ehr.), Pinnularia microstarum (Ehr.) Cleve, Pinnularia cf. lapponica (Hust.), E. cf. georgii e Fragilaria sp 1 foram registradas com as menores densidades (Fig. 3).

\subsection{Estrutura da assembleia de diatomáceas}

A densidade e a riquezas das diatomáceas apresentaram variação ao longo do testemunho, com média de 3.177,21 e desvio padrão de 591,08 valvas/ $\mu \mathrm{L}$. Os maiores valores destas variáveis foram registrados no Holoceno inicial, no nível a $701 \mathrm{~cm}$ de profundidade (18.404 valvas $/ \mu \mathrm{L}$, com riqueza de 100 espécies), seguido pelos níveis a $677 \mathrm{~cm}$ (15.682 valvas/ $\mu \mathrm{L}, 82$ espécies), $799 \mathrm{~cm}$ (13.650 valvas/ $\mu \mathrm{L}, 101$ espécies), 713 cm (13.040 valvas/ $\mu \mathrm{L}, 45$ espécies), $707 \mathrm{~cm}$ (11.604 valvas/ $\mu \mathrm{L}, 61$ espécies) e $662 \mathrm{~cm}$ (10.428 valvas/ $\mu \mathrm{L}, 81$ espécies) (Fig. 3). Neste mesmo intervalo de tempo foi registrado a valor mínimo da densidade, a $602 \mathrm{~cm}$ (18 valvas $/ \mu \mathrm{L}$, riqueza de 4 espécies). Outros valores baixos foram verificados nos níveis a $103 \mathrm{~cm}$ (52 valvas/ $\mu \mathrm{L}, 7$ espécies), $468 \mathrm{~cm}$ (62 valvas/ $\mu \mathrm{L}, 21$ espécies), 55 cm (65 valvas/ $\mu \mathrm{L}, 7$ espécies), $31 \mathrm{~cm}$ (71 valvas/ $\mu \mathrm{L}, 19$ espécies) e $306 \mathrm{~cm}$ (71 valvas/ $\mu \mathrm{L}, 24$ espécies), entre o Holoceno médio e final (Figs. 3, 4).

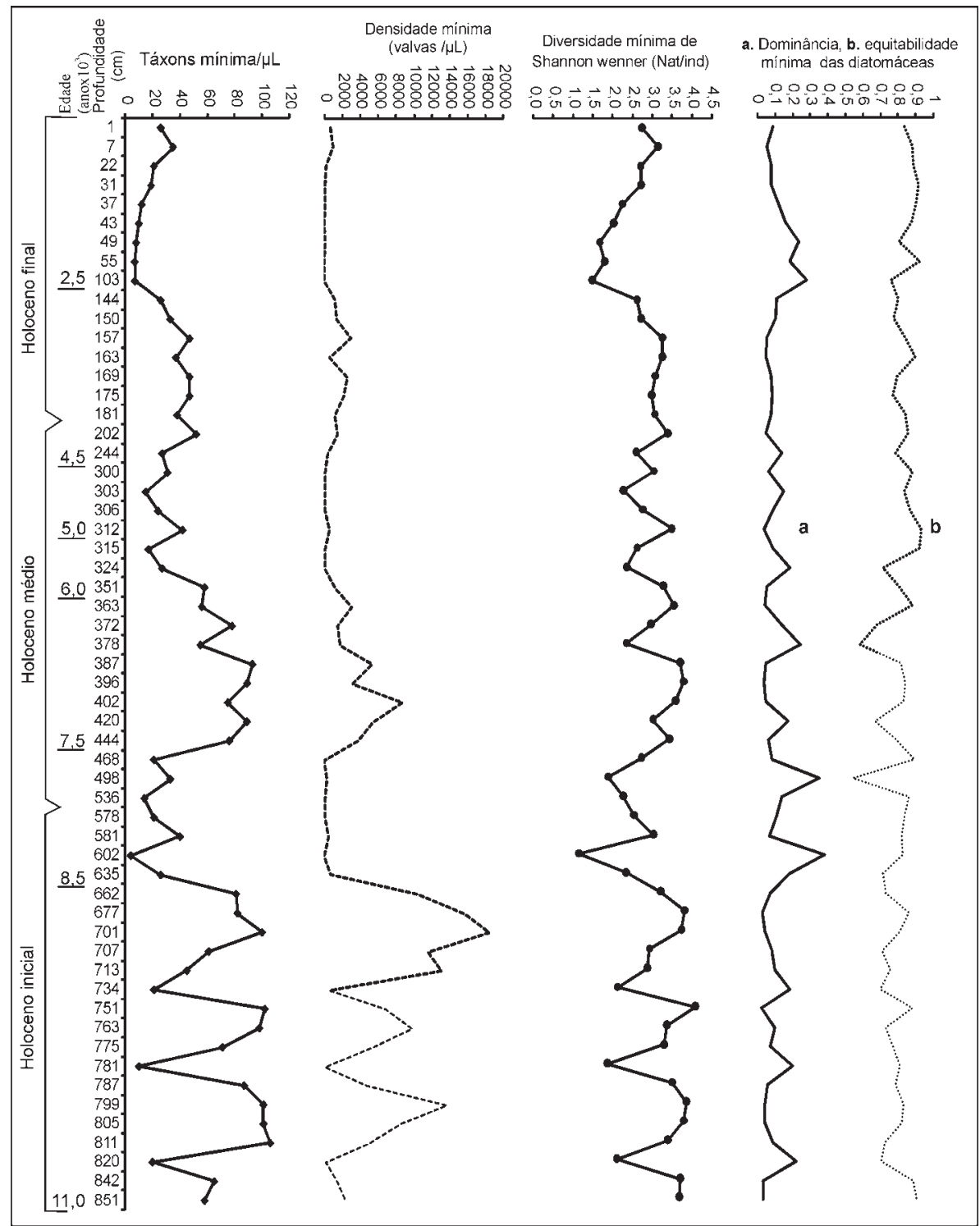

Figura 4. Variação dos táxons mínimos, densidade, diversidade, dominância e equitabilidade da assembléia de diatomáceas holocênicas do testemunho LLG3, Bacia Llano Grande, Páramo de Frontino, Departamento de Antioquia, Colômbia. 
Os índices analisados sobre a estrutura da assembleia de diatomáceas ao longo do testemunho LLG3 mostraram variação. 0 número de táxons apresentou valor médio de 47,23 e desvio padrão de 4,07, com maior índice a $811 \mathrm{~cm}$ de profundidade, localizados no Holoceno final (Fig. 4).

A média da dominância é de 0,1 , com desvio padrão de 0,01 , máximo valor a $602 \mathrm{~cm}(0,38)$, referente ao Holoceno inicial, seguidos dos níveis a $498 \mathrm{~cm}(0,38)$, do Holoceno médio, e $103 \mathrm{~cm}(0,27)$, no Holoceno final. 0 menor valor da dominância foi registrado a $751 \mathrm{~cm}$ $(0,024)$, correspondente ao Holoceno inicial, seguido do nível 396 (0,038), do Holoceno médio (Fig. 3).

A equidade das assembléias apresentou média de 0,81, desvio padrão de 0,011, com máximo valor a 312 $\mathrm{cm}(0,935)$, no Holoceno médio, seguidos dos níveis 55 cm $(0,927)$, e pelos níveis a $315 \mathrm{~cm}$ e $31 \mathrm{~cm}(0,92$ cada), correspondentes ao Holoceno médio e final, respectivamente. 0 menor valor de equidade foi registrado a 498 cm $(0,54)$, seguido dos níveis a 378 com $(0,585)$ e 373 $\mathrm{cm}(0,679)$, todos referentes ao Holoceno médio (Fig. 4).

A análise de proporções não paramétrico (Qui-quadrada) nas densidades apresentou diferenças estatisticamente significativas entre as divisões do Holoceno, com $\mathrm{P}=0,012$ e $\infty=0,5$, ocorrendo segundo a prova de Kruskal-Wallis entre o Holoceno o final e o Holoceno inicial (Fig. 5).

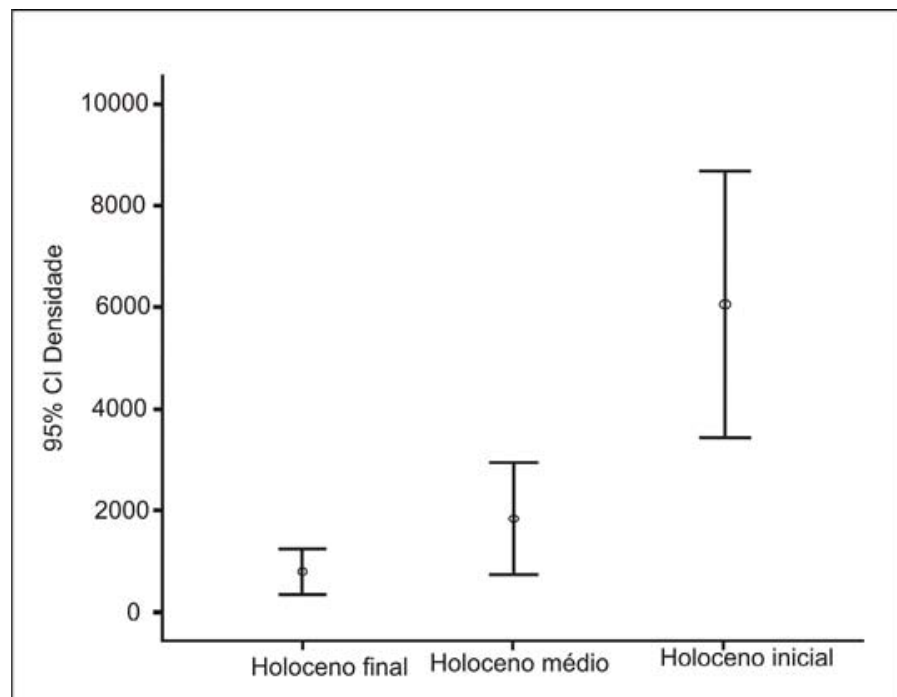

Figura 5. Análise comparativa da densidade das diatomáceas nas divisões do Holoceno (Anova de uma via) do testemunho (LLG3) na Bacia Llano Grande, Páramo de Frontino Departamento de Antioquia, Colômbia.

\section{Discussão dos resultados}

\subsection{Composição e estrutura da comunidade}

A maior riqueza dos táxons (37\%) e a densidade registrada para o gênero Eunotia são resultados esperados para o ecossistema estudado (Fig. 2), uma vez que o gênero é exclusivo de água doce. Embora algumas de suas espécies ocorram em ambientes eutróficos e básicos, maior diversidade e riqueza de espécies do gênero são registradas em ambientes ácidos e de baixa condutividade independente da latitude (Round et al., 1990; Lozano et al., 1999; Donato, 2001; Montoya et al., 2008, Wetzel, 2011). Estes mesmos resultados foram obtidos por Alles et al. (1991) e Schindler et al. (1996), em diferentes ecossistemas de turfa e pântanos de altitude média da Europa. Além disso, geralmente as espécies de Eunotia são de hábito epífito ou metafíton, predominando nos ecossistemas oligotróficos.

Segundo Velásquez (2005), o lago da Bacia de Llano Grande apresentou colonização por macrófitas submersas e emergentes nos últimos 4.000 anos, o que também foi constatado por Jojoa (2007), para o Holoceno médio do mesmo ecossistema. É possível que esta condição seja característica de todo o Holoceno. Em termos de riqueza em nível genérico, Eunotia foi seguido pelos gêneros Pinnularia, táxon epipélico e epífito abundante em ambientes ácidos, por Encyonopsis e Encyonema, gêneros epífitos, epilíticos, e metafíticos, e por Gomphonema, gênero haptobêntico (Round et al., 1990). Navicula, Brachysira e Frustulia também apresentaram riqueza destacada ao longo do testemunho. 0 primeiro é de hábito epipélica e/ou epilítica; Brachysira é de hábito metafítica, epipélica e/ou epífito, com apenas uma espécie (Brachysira aponina) de hábitat marinho. Espécies deste gênero podem ser abundantes em águas ácidas, distróficas, com baixa condutividade, enquanto outras abundam em águas mais alcalinas. Estas espécies não ocorrem em ecossistemas eutróficos, saprófitos e com acidificação antrópica, embora o gênero tenha distribuição cosmopolita (Lange-Bertalot \& Moser, 1994). Frustulia constitui gênero epipélico ou associado a macrófitas, em ecossistemas d'água doce a salobros, ácidos e turfosos (Round et al., 1990) (Fig. 2).

Em estudos de lagos de alta altitude da Colômbia, Lozano et al. (1999), Donato (2001), Abril (2007), Sierra (2007), Ramírez \& Plata-Diaz (2008), Barbosa (2009), dentre outros, registraram muitas das condições ambientais requeridas pelos gêneros verificados neste trabalho e expostos anteriormente, o que pode explicar a riqueza registrada.

A maior densidade, diversidade e riqueza de espécies registradas no Holoceno inicial podem corresponder com um ecossistema com ampla zona limnética, profundo e borda colonizada com macrófitas que favoreceram a assembleia de diatomáceas existentes. Contudo segundo Sierra-Arango (2013), os momentos de estratificação e mistura da coluna d'água, o transporte e o consumo de herbívoros afetaram tafonomicamente as frústulas e originaram para este intervalo o mais alto registro de fragmentação e dissolução das mesmas. Todos esses processos atuariam ao mesmo tempo no lago e poderiam acelerar o desaparecimento e/ou a extinção de 70 táxons na coluna d'água e no sedimento, sejam as espécies locais ou aquelas advindas por meio de riachos existentes. Além disso, para a metade deste intervalo, os eventos que influenciaram negativamente 
a estrutura e a composição da assembleia de diatomáceas foram mais intensos, relacionados a 70 espécies restritas e à morte de quase toda a assembleia e/ou a diminuição da sua densidade, sem recuperação (Fig. 3).

0 leve aumento estabelecido da densidade, da riqueza e da composição da assembleia de diatomáceas no trecho correspondente à metade do Holoceno médio (Figs. 3, 4) é devido aos novos aportes de cinzas que, segundo Parra (2005), originaram um depósito de $1 \mathrm{~cm}$ no registro sedimentar. Como consequência, 38 táxons aparecem pela primeira vez na coluna sedimentar, incluindo 30 restritos ao Holoceno médio e 8 alcançando o Holoceno final (Fig. 3), ocasionando aumento da riqueza de espécies, oscilações marcadas na diversidade e um leve aumento da densidade (Fig. 4). Estes fatos explicam a maior densidade de T. flocculosa nos níveis a 420, 378 e $372 \mathrm{~cm}$ de profundidade, correspondentes ao Holoceno médio (Fig. 3), uma vez que a espécie necessita de uma alta relação de Si/P para sua reprodução.

Para o final do Holoceno médio, Seltzer et al. (1995), Haug et al. (2001), Sosa-Nájera et al. (2010), Velásquez \& Hooghiemstra (2013), dentre outros, relatam um período de seca global, ao redor dos 5.000 anos AP. Este evento, possivelmente causou o desaparecimento de 100 táxons, não registrados no Holoceno final, incluindo 30 exclusivos ao Holoceno médio e 70 ocorrentes entre o Holoceno inicial e médio (Fig. 3).

Os processos tafonômicos (fragmentação, dissolução, piritização e laminação) identificados na bacia e descritos por Sierra-Arango (2013) e Sierra-Arango et al. (2014) também contribuíram para o desaparecimento dos táxons do testemunho, uma vez que iniciam a destruição da frústula e em estado avançado impedem a identificação e quantificação dos espécimes, incluindo as diatomáceas cêntricas, as quais, segundo Gersonde \& Wefer (1987) e Ryves et al. (2006), apresentam alta resistência à fragmentação e dissolução. Estas variáveis tafonômicas e a seca podem ser responsáveis pela diminuição drástica da densidade e da riqueza de espécies, bem como pelo desaparecimento ou extinção de outros táxons da coluna sedimentar. A composição e a estrutura da assembleia de diatomáceas no Holoceno final foram influenciadas negativamente pela diminuição da profundidade, alto consumo e pela formação da turfeira atual, podendo ter empobrecido registro fóssil mais (Fig. 3).

0 aumento da densidade no intervalo entre 200 e $144 \mathrm{~cm}$ de profundidade (Holoceno final) pode corresponder a um maior volume d'água, associado com período de maior precipitação, promovendo a sobrevivência das diatomáceas cêntricas e penadas que sobreviveram ao evento de seca ocorrido na Bacia Llano Grande no final do Holoceno médio identificado por Velásquez (2005) e Velásquez \& Hooghiemstra (2013), ao consumo das diatomáceas por herbívoros (Abril, 2007), bem como à limitação por nutrientes inferidos neste trabalho. As diatomáceas sobreviventes apre- sentaram baixa densidade. A partir de novas precipitações e com o aumento do volume do corpo d'água, a densidade foi incrementada, em um novo processo de sucessão ecológica. A composição e a estrutura da comunidade desse intervalo do tempo se mostraram diferentes do intervalo imediatamente inferior (306 a $200 \mathrm{~cm}$ ) (Figs. 3 e 4). Sob novas condições ambientais, foram registradas, pela primeira vez na bacia, táxons como Pinnularia cf. abaujensis, Eunotia paludosa, Brachysira sp. 3, Encyonema perpusillum, E. georgii, Eunotia sp. 4, Frustulia sp. 2, Neidium sp. 2. Por outro lado, Brachysira cf. linearlanceolata, Eunotia sp. 11, Eunotia sp. 24, Brachysira sp. 5, Eunotia sp. 26, Kobayasiella subtilissima, Eunotia pseudosudetica, Eunotia sp. 23 e Eunotia sp. 30 foram registradas na Bacia Llano Grande entre o Holoceno médio e final (Fig. 5).

A baixa densidade de diatomáceas reportada para os últimos níveis analisados do testemunho pode ser correlacionada com a perda da lâmina d'água (Sierra-Arango et al., 2014), atuação de herbívoros (Abril, 2007) e à formação da turfeira atual. Além disso, segundo Velásquez (2005), Donato et al. (2006) e Rangel-Ch (2010), os páramos da Colômbia são muito úmidos e frios, o que mantém o ambiente saturado de água, condição ambiental, que tem favorecido a permanência atual da turfeira da Bacia Llano Grande, com o incremento de macrófitas, vegetação de pântanos, e outras plantas de hábito mais terrestres descritos por Jojoa (2007) na bacia, indicando diminuição do nível d'água. Estas novas condições podem explicar o registro de espécies penadas de hábito perifítico nos últimos centímetros do testemunho.

\subsection{Permanência das espécies de diatomáceas}

As 51 espécies com maior permanência no lago da Bacia Llano Grande ao longo do Holoceno (Fig. 3) toleram condições físicas, químicas e de temperatura d'água, ou estão relatadas para ambientes ácidos (Round, et al., 1990; Lange-Bertalot \& Moser, 1994). Além disso, em sua maioria são espécies cosmopolitas, o que pode explicar sua permanência no lago, embora tenham sido verificadas perturbações naturais locais e externas da bacia, que modificaram a composição e a estrutura das diatomáceas ao longo do Holoceno.

A recorrência de espécies é interpretada como devida à nova sucessão ecológica e/ou de recuperação da densidade (Fig. 3). A maior ou menor densidade das diatomáceas revela a magnitude de cada evento de distúrbio e/ou da perturbação, enquanto o tempo para recuperação pode indicar o tempo de estabilização das novas condições físicas e químicas e/ou de estado trófico, seca e/ou colonização de macrófitas (Fig. 4).

Repetidas sucessões foram registradas na assembleia, com grande troca na composição taxonômica e variação na estrutura, cuja consequência foi a diferença estatística significativa na densidade entre o Holoceno inicial e o final (com p =0,012 e $\infty$ de 0,05) (Fig. 5), in- 
dicando alta variação e instabilidade ambiental. Além disso, acredita-se que as diatomáceas cêntricas registradas são espécies muito resistentes, generalistas e de fácil adaptação às mudanças ambientais, o que explica a recuperação parcial da densidade após os eventos drásticos ocorridos na bacia e/ou no lago, incluindo uma perturbação catastrófica para toda a comunidade existente $(602 \mathrm{~cm})$ (Fig. 3). Além disso, a composição e a estrutura da assembleia foram totalmente diferentes daquelas registradas no intervalo entre 851 e $665 \mathrm{~cm}$ (Figs. 3 e 4). Depois dessa perturbação, a assembleia foi diminuindo gradualmente sua densidade e riqueza durante o Holoceno médio e final, embora durante o Holoceno médio tenha ocorrido melhoria nas condições ambientais e aporte externo de novos nutrientes (Figs. 3 e 5).

No entanto, as 67 espécies restritas no Holoceno inicial não resistiram à magnitude das perturbações e desapareceram, indicando ambiente não favorável para a associação das espécies penadas, com densidade muito menor, subordinada às formas cêntricas (Fig. 3); dessas, 29 não apresentaram perturbação tafonômica, e só ocorreram em 6 amostras das 21 analisadas. Contudo, o tempo correspondente entre a deposição de um nível estratigráfico e outro permite regenerações sucessivas de cada espécie, de modo que muitos eventos drásticos poderiam não deixar registro. Dessa forma, pode-se inferir que os distúrbios e/ou perturbações que atingiram a Bacia Llano Grande durante o Holoceno inicial e/ou médio podem ter sido longos ou suficientes para promover a redução do potencial reprodutivo de determinadas espécies e seu desaparecimento, bem como o estabelecimento de novas assembleias constituídas, em sua maioria, por novos táxons.

Também foi registrada influência de efeitos tafonômicos (fragmentação, dissolução), que favoreceram a perda do registro fóssil ao longo do testemunho (Sierra-Arango, 2013). Para o Holoceno inicial, a fragmentação das frústulas é principalmente atribuída ao transporte longitudinal dos ecossistemas lóticos, favorecendo a posterior dissolução enquanto é transportada até o lago e, após, na coluna d'água. Diatomáceas autóctones do sistema lacustre também estão sujeitas a ambos os efeitos tafonômicos. A desmineralização do lago e a limitação da sílica devido à sedimentação da cinza vulcânica contribuem no processo de dissolução. Para o Holoceno inicial, acredita-se que o ecossistema apresentou alta produtividade, devido ao abundante registro de frústulas, o que é compatível com as idéias de Margalef (1983), Reynolds (1984) e Wetzel (2001).

Outras espécies foram observadas quimicamente transformadas ou em processos de transformação (laminação e piritização), não contabilizadas devido às perdas das características diagnósticas, mas que auxiliaram a interpretação da estratificação e o conteúdo do oxigênio no lago (Sierra-Arango, 2013).

0 registro das 144 espécies com taxonomia aberta (incluindo as 95 assinaladas como "sp." e os 49 tá- xons com dúvidas a determinadas espécies, cf.) foi incrementado a partir do Holoceno médio, embora com densidade muito menor que a registrada no Holoceno inicial (Fig. 3). Possivelmente, estes táxons correspondem a variedades intraespecíficas, como uma resposta adaptativa a períodos de tempos com menos variações extremas no ambiente, o que é interpretado por Gribbin \& Lamb (1978) como resposta à estabilização das condições ambientais em nível global.

Pela localização geográfica, os ecossistemas de altitude correspondem a ambientes extremos (Margalef, 1983; Wetzel, 2001), geralmente isolados geograficamente. 0 isolamento geográfico é uma das teorias mais documentadas na literatura como causa de especiação. Embora seja necessário um longo tempo para esse processo, há registros de rápida evolução para o Holoceno em lagos nestas condições (Margalef, 1983; Bramburger, 2010). A exposição das espécies à radiação ultravioleta, a variação química d'água decorrente dos aportes externos de cinzas, bem como a limitação de silício, entre outros, deve ter proporcionado variações intraespecíficas, como respostas adaptativas ao ambiente. Por isso, o Páramo de Frontino deve ter constituído um ecossistema de rápida especiação de diatomáceas.

Segundo Metzeltin \& Large-Bertalot (1998), Sala et al. (2008b) e Wetzel (2011), as diatomáceas tropicais são muito diversas, com associações distintas daquelas registradas em ecossistemas temperados. Além disso, como resultado da grande variação da topografia, e das condições físicas e químicas da coluna d'água, nos ecossistemas tropicais, as diatomáceas apresentam alto grau de endemismo, gerando listas de espécies identificadas em nível supra-específico (Donato et al., 1996; Donato, 2001; Montoya-M et al., 2008; Wetzel, 2011, entre outros), demonstrando necessidade de aprofundamento dos estudos taxonômicos.

\section{Conclusões}

Uma ampla variedade de diatomáceas foi constatada ao longo do testemunho, com o registro de 292 táxons. A riqueza taxonômica e a densidade das diatomáceas diminuíram da base para o topo, com 244 táxons no trecho correspondente ao Holoceno inicial, 213 ao Holoceno médio e 111 no Holoceno final. 0 alto número de espécies classificadas com nomenclatura indefinida em nível de espécie (sp. ou cf.) confirma que a biota da região tropical apresenta um alto grau de diversidade, riqueza taxonômica, com muitos aspectos sobre ecologia e dinâmica ainda desconhecidos. Essas deficiências são mais marcadas nos ecossistemas de altitude que se desenvolvem geograficamente isolados e com condições ambientais extremas. Como resultados podem ocorrer variações intraespecíficas, bem como especiação e/ou alta taxa de evolutiva, com alto grau de endemismo.

A composição e a estrutura das diatomáceas registradas no testemunho LLG3, perfurado no Páramo 
de Frontino apresentaram grande variação ao longo do Holoceno, com troca na composição, diminuição da riqueza taxonômica e densidade de espécies, como resposta às modificações ambientais em nível local e global, incluindo aportes externos de nutrientes, seca, desmineralização da coluna de água, herbivoria e efeitos tafonômicos. Esses últimos efeitos limitaram a identificação e a quantificação de determinados táxons ao longo do perfil. As variações são interpretadas como decorrentes de forte perturbação e/ou distúrbio nas assembleias, que determinaram a permanência de cada espécie no corpo lacustre. Ao longo da coluna sedimentar, foi registrado o desaparecimento sucessivo de 169 espécies.

De todas as perturbações inferidas ao longo do testemunho, aquela do final do Holoceno inicial foi a mais catastrófica para a assembleia de diatomáceas, sendo responsável pela morte de quase todos os indivíduos e pelo desaparecimento da maioria das espécies identificadas no intervalo entre 851 e $635 \mathrm{~cm}$ de profundidade. A partir deste último nível, a assembleia não recuperou sua composição e estrutura, embora haja registros de novas espécies. A desmineralização da coluna d'água decorrente do aporte de cinzas vulcânicas, com sedimentação durante um longo período de tempo, e a consequente limitação de nutrientes são interpretadas como as principais causas das perturbações.

Agradecimentos- Os autores agradecem a César Velásquez Ruiz por ceder as amostras do testemunho e sugestões apresentadas, a Lezilda Torgan pela confirmação taxonômica de alguns táxons registrados e aos revisores pelas contribuições. Este trabalho é parte da tese de doutoramento desenvolvida pela primeira autora junto ao Programa de Pós-graduação em Geociências da UFRGS, com recursos financeiros do CNPq (Processo 142223/2008-5), constituindo com a contribuição ao projeto FAPERGS 1012119.

\section{Referências}

Abril, R.G. 2007. Macroinvertebrados en dos cuerpos de agua del Páramo de Frontino (Antioquia), Colombia con énfasis en los Quironómidos (Diptera: Chironomidae). Medellín, 130p. Dissertação de Mestrado em Entomologia. Departamento de Ciências, Universidad Nacional de Colombia, Sede Medellín.

Abuhatab-Aragon, Y.A. 2011. Actividad metabólica diaria del biofilm en el sector medio de un rio de alta montaña, (Rio Tota, Boyaca, Colombia). Bogotá, 150p. Dissertação de Mestrado em Ciências Biológicas, Departamento de Biología, Universidad Nacional de Colombia, Sede Bogotá.

Alles, E., NorpeL-Schempp, M. \& Lange- Bertalot, H. 1991. Zur Systematik und okologie charakteristischer Eunotia-Arten (Bacyllariophyceae) in elektrolytarmen Bachoberlaufen. Nova Hedwigia, 53: 171-213.

Barbosa, M.G. 2009. Variación temporal del fitoplancton en la laguna sabanas del Páramo de Belmira, Antioquia. Colombia. Bucaramanga, 190p. Dissertação de conclusão do curso de Biologia, Escola de Biologia, Faculdade de Ciências, Universidad Industrial de Santander.

Barbosa, G.A \& Sierra-Arango, O.R. Variación temporal del fi- toplancton en la laguna sabanas del Páramo de Belmira, Antioquia. Colombia. Bucaramanga. Caldasia (submetido).

Bicudo, C.E.M. \& Menezes, M. 2006. Gêneros de algas de águas continentais do Brasil. São Carlos, Rima, 489p.

Bramburger, A. 2010. Mechanisms regulating the composition, structure and dynamics of biological communities: Insights from Freshwater Diatom Communities. Windsor, Electronic Theses and Dissertations, University of Windsor, $378 \mathrm{p}$.

Coesel, P.F.M. 1992. Desmid assemblies along altitude gradients in Colombia. Nova Hedwigia, 55: 353-366.

Chapin, F.S. \& Körner, Ch. 1995. Patterns, causes, changes and consequences of biodiversity. In Chapin, F.S. III \& Ch. Körner (Ed.). Arctic and alpine biodiversity: Patterns, causes and ecosystem consequences, Berlin, Springer-Verlag, p. 113-320.

Díaz-Quiróz, C. \& Rivera-Rendón, C.A. 2004. Diatomeas de pequeños ríos andinos y su utilización como indicadores de condiciones ambientales. Caldasia, 26(2): 381-394.

Donato-R, J.C. 2001. Fitoplancton de los lagos andinos del norte de Sudamérica (Colombia). Composición y factores de distribución. Bogotá, Academia Colombiana Ciencias Exactas Físicas Naturales. Colección Javier Álvarez Lleras 9, 110p.

Donato-R, J.C. 2004. Consideraciodonatones generales sobre el estado de los ambientes acuáticos de agua dulce en Colombia. In: Neiff, J.J. (Ed.). Humedales de Iberoamérica, Buenos Aires, CYTED, p. 226-235.

Donato-R, J.C., Gónzales, L.E. \& Rodríguez, C.L. 1996. Ecología de dos sistemas acuáticos de Páramo. Bogotá, Academia Colombiana Ciencias Exactas Físicas Naturales. Colección Javier Álvarez Lleras 9, 132p.

Donato-R, J.C., Rivera, C.A. \& Pinilla, G.A. 2006. Photosynthetic efficiency of phytoplankton in a tropical mountain lake, Colombia. Caldasia, 28(1): 57-66.

Falasco, E., Ector, L. \& Ciaccio, E. 2012. Alpine Fresh water ecosystem in a protected area: a source of diatom diversity. Hydrobiologia, 695: 233-251.

Franguelli, J. 1945. Las diatomeas del Platense. Revista del Museo de La Plata, 3(17): 1-226.

Gersonde, R \& Wefer, G. 1987. Sedimentation of biogenic siliceous particles in Antarctic waters from the Atlantic sector. Marine Micropaleontology, 11: 311-332.

Gribbin, J. \& Lamb, H.H. 1978. Climate Change in Historical times. In: Gribbin (Ed.). Climate Change, London, Cambridge University Press, p. 68-82.

Hammer, Ø., Harper, D.A.T. \& Ryan, P.D. 2001. PAST: Paleontological statistics software package for education and data analysis. Palaeontologia Electronica 4(1): 9pp.http://palaeo-electronica.org/2001_1/past/issue1_01.htm.

Haug, G.H., Hughen, K.A., Sigman, D.M., Peterson, L.C. \& Röhl, U. 2001. Southward migration of the intertropical convergence zone through the Holocene. Science, 293: 13041308.

Houk, V. 2003. Atlas of fresh water centric diatoms with a brief key and descriptions. Part. I. Melosiraceae, Orthoseiraceae, Paraliaceae and Aulacoseiraceae. Czech Phycology Suplement, 1:1-127.

Houk, V., Klee, R. \& Tanaka, H. 2010. Atlas of fresh water centric diatoms with a brief key and descriptions. Part. III. Stephanodiscaceaea, Cyclotella, Tertiarius, Discostella. Czech Phycology Suplement, 1: 1-498.

Husted, F. 1930. Bacillariophyta (Diatomeae). Berlim, Verlag 
Von Gustav Fischer, 468p.

Jaramillo, D. \& Parra, N. 1993. Aspectos biofísicos generales del Páramo de Frontino. Revista Instituto de Ciencias Naturales y Exactas, 4(2): 81-96.

Jojoa, U.L.M. 2007. Reconstrucción Paleoecológica de la vegetación y el clima durante el Holoceno Medio en el sector de llano Grande, Páramo Frontino, Antioquia, Colombia. Nariño, 130p. Dissertação de conclusão do curso de Biologia. Escola de Biologia. Universidad de Nariño.

Kinzie, R.A., Banasza, T.A \& Lesser, P.M. 1998. Effects of ultraviolet radiation on primary productivity in a high altitude tropical lake. Hydrobiologia, 385: 23-32.

Krammer, K. 1992. Die Gattung Pinnularia in Bavaria. Regensburg, $309 \mathrm{p}$.

Krammer, K. 1997a. Bibliotheca Diatomologica. Band 36. Die Cymbelloiden Diatomeen Allgemeines und Encyonema Part., Berlin, J. Cramer, 382p.

Krammer, K. 1997b. Bibliotheca Diatomologica. Band 37. Die Cymbelloiden Diatomeen Encyonema Part., Encyonopsis and Cymbellopsis. Berlin, J. Cramer, 469p.

Krammer, K. 2000. The genus Pinnularia. in: Lange-Bertalot (Ed.). Diatom of Europa 1. Berlin, A.R.G. Gentner Verlag, Roggell, 703p.

Krammer, K. \& Lange Bertalot, H. 1986. Bacillariophyceae 2. Berlin, Gustav Fisher Verlag, 876p.

Krammer, K. \& Lange Bertalot, H. 1991a. Bacillariophyceae 3 Centrales, Fragilariaceae, Eunotiaceae. Berlin, Gustav Fischer Verlag. 576 p.

Krammer, K. \& Lange Bertalot, H. 1991b. Bacillariophyceae 4: Achnanthaceae, Navicula (Lineolatae) und Gomphonema. Berlin, Gustav Fischer Verlag, 436p.

Krammer, K. \& Lange Bertalot, H. 1997a. Bacillariophyceae 1. Naviculaceae. Berlin, Gustav Fischer Verlag, 876p.

Krammer, K. \& Lange Bertalot, H. 1997b. Bacillariophyceae 2. Bacillariaceae, Epithemiaceae, Surirellaceae. Gustav Fischer Verlag, 610 p.

Lange-Bertalot, H. 2007. Iconographia Diatomologica Vol. 18. Tropical Diatoms of South America II. Diversity-Taxonomy-Biogeography. Berlin, A.R.G. Gantner Verlag K.G, 867p.

Lange-Bertalot, H. \& Moser, G. 1994. Bibliotheca Diatomilogica, Band 29. Brachysira. Berlin, J. Cramer, 212p.

Lange-Bertalot, H. \& Genkal, S.I. 1999. Diatom from Siberia 1. Berlin, A.R.G. Gantner Verlag K.G, 301p.

Lange-Bertalot, H., Külbst, K., Lauser, T., Nörpel-Schempp, M. \& Willmann, M. 1996. Iconographia Diatomologica, annotated diatom micrographs Diatom Taxa Introduced by Georg Krasske - Documentation a Revision. Berlin, Koeltz Scientific Books, 358p.

Lange-Bertalot, H. Kusber, W \& Jahn, R. 2013. Annotated list of diatom names by Lange-Bertalot and Co-workers. www. Algaterra,org/names_version3_0.pdf 103p.

Lange-Bertalot, H., Bak, M. \& Witkowski, A. 2011. Diatoms of Europe. V.6. Eunotia and some related genera. Berlin, Königstein, Koeltz Scientific Books, 747p.

Leavitt, P.R., Cumming, B.F., Smol, J.P., Reasoner, M., Pienitz, R. \& Hodgson, D.A. 2003. Climatic control of UV radiation effects on lakes. Limnology and Oceanography, 48: 20622069.

Lewis, J.R.W. 2002. Causes for the high frequency nitrogen limitation in tropical lakes. Verhandlungen Internationale Vereinigung für Theoretische und Angewandte Limnologie, 28: 210-213.

López-Merino, L., Moreno, A., Leira, M., Sigró, J., González-Sampériz, P., Valero-Garcés, B.L. \& López-Sáez, J.A. 2011.
Two hundred years of environmental change in Picos de Europa National Park inferred from sediments of Lago Enol, northern Iberia. Journal of Paleolimnology, 46(3): 453-467.

Lozano, C.G., Parra, L.N., Moro R.S. \& Ramírez, J.J. 1999. Inferencias paleolimnológicas del holoceno con base en diatomeas en la laguna Puente Largo, Páramo de Frontino, Antioquia. In: Floréz, M.T. \& Lozano, C.G. (Ed.). Silicofósiles altoandinos. Medellín, Universidad Nacional de Colombia, p. $57-116$

Margalef, R. 1983. Limnología. Barcelona, Ediciones Omega, S. A. 1050 p.

Mejia, R.D.M. 2011. Diatomeas perfíticas y algunas características limnológicas de um humedal hurbano em la sabana de Bogotá. Bogotá, 114p. Dissertação de Mestrado em Ciências Biológicas. Departamento de Biologia, Universidad Nacional de Colombia, sede Bogotá.

Metzeltin, D. \& Lange-Bertalot, H. 1998. Iconographia Diatomologica. Tropical Diatoms of South America I. Vol. V. Berlin, Koeltz Scientific Books, 695p.

Montoya-M, Y., Ramírez-Restrepo, J.J. \& Seguecin-Moro, R. 2008. Diatomeas perifíticas de la zona de ritral del Rio Medellín (Antioquia), Colombia. Actualidades Biológicas, 30(88): 185-197.

Morales, E.A., Ector, L., Fernández, E., Novais, M.H., Hlúbiková, D., Hamilton, P.B., Blanco, B., Vis, M.L. \& Kociolek, P. 2011. The genus Achnanthidium Kutz. (Achnanthales, Bacillariophyceae) in Bolivian streams: a report of taxa found in recent investigations. Algological Studies, 136/137, 89-130.

Morales-Duarte, S.J., Donato-Rendón, J. \& Castro-Rebollero, M.I. 2010. Respuesta de Navicula rhynchocephala (Bacillariophyuceae) a incrementos de nutrientes en un Arroyo andino (Colombia). Acta Biológica Colombiana, 15(2): 73-78.

Muñoz, P. 2012. Holocene climate variability in tropical South America: case history from a high-mountain wet zone in NW Colombia based on palynology and X-ray microfluorescence. Genebra, 250p. Tese de Doutorado University of Switzerland.

Parra, S.L.N. 1991. Geología glacial del Páramo de Frontino. Medellín, 123 p. Universidad Nacional de Colombia, Departamento de Ciencias de la Tierra, 123p (Documento interno).

Parra, S.L.N. 2005. Análisis Facial de Alta resolución de sedimentos del Holoceno Tardío en el Páramo de Frontino, Antioquia, Colombia. Bogotá, 202p.Tese de Doutorado. Departamento de Biología. Universidad Nacional de Colombia, sede Bogotá

Patrick, R. \& Reimer, C.W. 1966. The Diatom The United States. Philadelphia, The Academy of Sciences of Philadelphia. 688p.

Patrick, R., Reimer. C.W. \& Yong, G.S. 1975. The Diatoms of the United States. Pennsylvania, The Academy of Natural Sciences of Philadelphia, 213p.

Pedraza-Garzón, E. \& Donato-Rendón, J. 2011. Diversidad y distribución de diatomeas en un arroyo en un arroyo de montaña de los Andes de Colombia. Caldasia, 33(1): 177191.

Ramírez, A.M. \& Plata-Diaz, Y. 2008. Diatomeas perifíticas en diferentes tramos de dos sistemas lóticos de alta montaña (Páramo de Santurbán, Norte de Santander, Colombia) y su relación con las variables ambientales. Acta Biológica Colombiana, 13(1): 199-216.

Rangel-Ch, J.O. 2010. Colombia Diversidad Biótica X: Cam- 
bio global (natural) y climático (Antrópico) en el Páramo Colombiano. Bogotá, Universidad Nacional de Colombia-Instituto de Ciencias Naturales, 556p.

Reichardt, E. \& Lange-Bertalot, H. 1991. Taxonomische Revision des Artenkomplexes um Gomphonema angustum - $G$. dichotomum - G. intricatum - G. vibrio und ähnliche Taxa (Bacillariophyceae). Nova Hedwigia, 53(3-4):519-544.

Reynolds, C.S. 1984. Ecology of Freshwater Phytoplankton. Cambridge, University Press, 384p.

Rivera, C., \& Donato-R, J. (2008). Influencia de las variaciones hidrológicas y químicas sobre la diversidad de diatomeas bénticas. In: Donato-R (Ed.). Ecología de un río de montaña de los Andes Colombianos (Rio La Tota, Boyacá). Bogotá, Universidad Nacional de Colombia, p. 83-102.

Ryves D.B., Battarbee, R.W., Juggins, S., Fritz, S.C. \& Anderson, N.J. 2006. Physical and Chemical predictors of diatom dissolution in freshwater and saline lake sediments in North America and West Green land. Limnology and Oceanography, 51:1355-1368.

Round, F.E., Kraunfor, R.M. \& Mann, D.G. 1990. Diatom: Biology and Morphology of the Genera. Cambridge, University Press, 752p.

Rumrich, U., Lange-Bertalot, H. \& Rumrich, M. 2000. Iconografia. Diatomologica 9:1. Diatoms of Andes, Berlin, A.R.G. Gantner Verlag K.G, 673p.

Sala, S.E., Duque, S.R., Nuñez-Avellaneda, M. \& Lamaro, A.A. 2002. Diatom from the Colombian Amazon: same species of the genus Eunotia (Bacillariophyceae). Acta Amazonica, 32(4): 589-603.

Sala, S.E., Nuñez-Avenallena, M. \& Vouilloud, A.A. 2008a. Ultrastructure of the frustule of Urosolenia species from the Colombian and Peruvian Amazon: U. delicatissima spec. nov., U. amazonica sp. nov. and U. braunii (hustedt) Rott and Cling. Diatom Research, 23(1): 59-69.

Sala, S.E., Ramírez, J.J. \& Plata, D.Y. 2008b. Diatoms from lentic and lotic systems in the Antioquia, Chocó and Santander Deparments in Colombia. Revista Biology Tropical, 56(3): 1159-1178.

Seltzer, G.O., Robdell, D.T. \& Abbott, M. 1995. Andean glacial lake and climate variability since the last glacial maximum. Bulletin de L'Institut Francais d'Etudes Andines, 24(3): 539-549.

Schindler, D.W., Bayley, S.E., Parker, B.R., Beaty, K.G., Cruikshank, D.R., Fee, E.J., Schindler, E.U. \& Stainton, M.P. 1996. The effects of climatic warming on the properties of boreal lakes and streams at the Experimental Lakes Area, northwestern Ontario. Limnology and Oceanography, 41: 1004-1017.

Schmidt, A.1874-1959. Atlas der Diatomaceen-Kunde. O.R. Reisland. Leipzig, 480 p.

Sierra, A.O.R. 2007. Variación espacio-temporal de la familia Bacillariophyceae (diatomeas) en más de 1400 años de evolución del humedal de Jaboqué, Engativa, Cundinamarca. Colombia. Medellín, 210p. Tese de Mestrado em Biologia, Departamento de Biologia, Universidad de Antioquia.

Sierra, A.O.R. \& Monsalve, M.C.A. 2005. Zonificación trófica del humedal Jaboqué, con base en la familia Bacillariophyceae, Engativá. In Rangel-Ch., J.O. (Ed.). Investigación aplicada en restauración ecológica en el humedal de Jaboqué. Bogotá, Convenio Acueducto de Bogotá-Universidad Nacional de Colombia. p. 1-23.

Sierra-Arango, O.R. 2013. Análise paleoecológica e tafonômica de alta resolução em depósitos holocênicos no Páramo de Frontino, Antioquia, Colômbia, com base em diatomáce- as. Porto Alegre, 231p. Tese de Doutorado, Programa de Pós-Graduação em Geociências, Instituto de Geociências, Universidade Federal do Rio Grande do Sul.

Sierra-Arango, O.R., Souza, P.A. \& Velázquez, R.C.A. 2014. Taphonomic signatures and paleoecological implications of Holocene diatom assemblages in the Llano Grande Basin, from the Frontino Páramo, northwestern Andes Cordillera, Colombia. Revista Brasileira de Paleontologia, 17(2): 123-140.

Simonsen, R. 1974. The Diatom plankton of the Indian Ocean Expedition of the R. V. "Meteor" in: Moro, R.S. \& Santi, V. 1999. Avaliação das técnicas de oxidação comumente empregadas na limpeza de valvas silicosas. Boletim da Sociedade Brasileira de Limnologia, 1: 17-25.

Sosa-Nájera, S., Lozano-García, S., Roy, P.D. \& Caballero, M. 2010. Registro de sequías históricas en el occidente de México con base en el análisis elemental de sedimentos lacustres: El caso del lago de Santa María del Oro. Boletín de la Sociedad Geológica Mexicana, 62 (3): 437-451.

Tilman, D. 1982. Resource Competition and Community Structure. (Monographs in Population Biology; 17). Princeton, University Press, Princeton New Jersey, 299p.

Valero-Garcés, B., Zeroual, E. \& Kelts, K. 1998. Arid phase in the western Mediterranean region during the 879 last glacial cycle reconstructed from lacustrine records. In: Benito, G., Baker, V.R. \& Gregory, K.J. (Eds.), Paleohydrology and Environmental Change. Wiley, London, p. 67-80. Velásquez, R.C.A. 2005. Paleoecología de alta resolución del Holoceno tardío en el páramo de frontino, Antioquia. Bogotá, 199p. Tese de Doutorado. Departamento de Biología. Universidad Nacional de Colombia.

Velásquez-R, C.A. \& Hooghiemstra, H. 2013. Pollen-based 17Kyr Forest dynamics and climate change from the Western Cordillera; no-analogue associations and temporarily lost biomes. Review of Paleobotany and Palynology, 194: 38-49

Velez, M.A., Hooghiemstra, H., Metcalfe, S., Martinez, I., Mommersteeg, H. 2003. Pollen- and diatom based environmental history since the Last Glacial Maximum from the Andean core Fuquene-7, Colombia. Journal of Quaternary Science, 18(1): 17-30.

Vélez, M.I., Wille, M., Hooghiemstra, H. \& Metcalfe, S. 2005a. Integrated diatom-pollen based reconstruction of environmental change from Laguna Las Margaritas in the western Colombian savanna area. The Holocene, 15: 1184-1198

Vélez, M.I., Hooghiemstra, H. \& Metcalfe, S. 2005b. Fossil and modern diatom assemblages from the savanna lake El Piñal, Colombia: an environmental reconstruction. Diatom Research, 20: 387-407.

Vélez, M.I., Berrío, J.C., Hooghiemstra, H. \& Metcalfe, S. 2005c. Palaeoenvironmental changes during the last ca. 8529 cal yr in the dry forest ecosystem of the the Patía valley. Palaeogeography, Palaeoclimatology, Palaeoecology. 216: 279-302.

Vélez, M.I., Hooghiemstra, H. Metcalfe, S. Berrío, J. \& Wille, M. 2006. Late Glacial and Holocene palaeolimnological records from four lakes in Colombia, northern South America. Palaeogeography, Palaeoclimatology, Palaeoecology, 234: 81-96.

Vouilluod, A.A., Sala, S.E., Avalleneda, D.M. \& Duque, S.R. 2010. Diatoms from the Colombian and Peruvian Amazon: the genera Encyonema, Encyonopsis and Gomphonema (Cymbelales: Bacyllariophyceae). Revista Biology 
Tropical, 58(1): 45-62.

Wetzel, C.E. 2011. Biodiversidade e distribuição especial de diatomáceas (Bacillariophyceae) na bacia hidrográfica do Rio Negro, Amazonas, Brasil. São Paulo, 1922p. Tese
Doutorado, Instituto de Botânica, da Secretaria do Meio Ambiente, Universidade de São Paulo.

Wetzel, R.G. 2001. Limnology Lake y River Ecosistems. Califonia, Academic Press, 1120p.

Manuscrito 523.

Editora: Marina Bento Soares. 
